\title{
The art and science of non-invasive ventilation
}

\section{Miquel Ferrer}

Department of Pneumology, Thorax Institute, Hospital Clinic - Institut d'Investigacions Biomèdiques August Pi i Sunyer (IDIBAPS), University of Barcelona, Barcelona, Spain

Centro de Investigaciones biomedicas En Red-Enfermedades Respiratorias (CibeRes CB06/06/0028)-ISCIII

\author{
Address for correspondence: \\ Miquel Ferrer, MD, PhD \\ Senior Consultant \\ RIICU, Department of Pneumology \\ Hospital Clinic, IDIBAPS \\ Villarroel 170 \\ 08036 Barcelona, Spain \\ Phone/Fax: +34 932275549 \\ E-mail: miferrer@clinic.ub.es
}

\section{Summary}

Non-invasive ventilation (NIV) is one of the most relevant recent advances in the management of patients with severe acute respiratory failure (ARF). NIV is considered a standard of care for the management of hypercapnic ARF in patients with acute exacerbation of chronic obstructive pulmonary disease. With an appropriate selection of patients, NIV can reduce the need for invasive mechanical ventilation, mortality and length of stay. Patients with severe hypoxemic ARF have in general a lower likelihood to need tracheal intubation when NIV as a support for ARF is added to the standard medical treatment. However, the effects of NIV on mortality are less evident, and the heterogeneity of the different published studies suggests that the efficacy may be different among different populations. The optimal time for intubation after NIV failure remains a challenging issue due to increasing evidences on the relationship between delayed intubation and excess mortality in these populations. In intubated patients with preexisting lung disease, the use of NIV in order to advance extubation during difficult and prolonged weaning can result in reduced periods of endotracheal intubation, complication rates and improved survival. Moreover, NIV immediately after extubation is effective in avoiding respiratory failure after extubation and improving survival in patients at risk for this complication, particularly those with chronic respiratory disorders, cardiac co-morbidity, and hypercapnic respiratory failure.

KEY WORDS: non-invasive ventilation, acute respiratory failure, weaning, hypoxemic respiratory failure, hypercapnic respiratory failure.

\section{Introduction}

Non-invasive ventilation (NIV) is one of the most relevant recent advances in the management of patients with severe acute respiratory failure (ARF). Non-invasive ventilation is ventilatory support through the upper airways of patients with an interface, usually a mask; therefore, tracheal intubation or a tracheostomy is not needed. The benefits of NIV appear to be the consequence of avoiding tracheal intubation and the associated morbidity and mortality $(1,2)$.

There are several potential advantages for the use of NIV. Some patients can be managed out of an intensive care unit (ICU), a par-
Non-invasive ventilation is a first-line intervention in patients with severe exacerbation of COPD and hypercapnic respiratory failure, and those affected of acute cardiogenic pulmonary oedema. ticularly stressful environment, with additional benefits in reducing the occupation of ICU beds and related costs. Ventilatory support can be intermittent and therefore withdrawal of NIV can be gradual. These patients can cooperate in respiratory therapy; they can receive nebulised therapy, expectorate and communicate with staff and their relatives. However, there are limitations for NIV. Unnecessary delay in intubation of those patients who fail with NIV treatment is associated with worse outcome (3). Some patients do not tolerate the mask due to claustrophobia or other causes, and nasal bridge skin breakdown can occur and difficult the use of NIV.

Non-invasive ventilation is now considered as a firstline intervention in selected patients with severe exacerbation of chronic obstructive pulmonary disease (COPD) and hypercapnic respiratory failure $(4,5)$, and those affected of acute cardiogenic pulmonary oedema (CPO) (6). Immunosuppressed patients have poor outcome when they develop pulmonary infiltrates and hypoxemic ARF; in these patients, NIV seems to decrease the needs for intubation and the related morbidity and mortality $(7,8)$. Non-invasive ventilation has also been used in different indications during withdrawal of invasive mechanical ventilation (IMV) such 
as advancing extubation in patients with difficult or prolonged weaning and in the management or prevention of post-extubation respiratory failure. Conversely, the efficacy of NIV in patients with different types of hypoxemic ARF is less evident from controlled clinical trials (9), with controversial results when all these trials are analysed together. Robust randomised clinical trials $(R C T)$ are scarce, hence explaining why absence of specific recommendations often predominates in the evidence-based guidelines (10).

This review article will focus on the use of NIV in 3 different conditions: 1) COPD exacerbations and other causes of hypercapnic ARF; 2) patiens with hypoxemic ARF; and 3) withdrawal of IMV.

\section{Non-invasive ventilation in COPD exacerbations and other causes of hypercapnic acute respiratory failure}

Chronic obstructive pulmonary disease exacerbation is one of the most frequent causes of hospital admission from emergency rooms (11); the majority of patients with advanced COPD may require hospital admission (12). Exacerbations are important events during the natural history of the disease (13), with worsening of lung function and health related quality of life (14). A COPD exacerbation that needs hospital admission is associated with poor outcome, with $34 \%$ readmission rate and $14 \%$ mortality rate after 3 months (15). Non-invasive ventilation can be implemented in different settings.

Hypercapnic ARF secondary to COPD exacerbation is the best established indication for NIV. The majority of contraindications for NIV previously described were considered exclusion criteria in controlled clinical trials; since there are no evidences for associated complications, they should be considered as relative rather than absolute. Settings that require special attention during NIV include recent gastrointestinal or upper airway surgery, inability to protect the airways, hemodynamic instability, decreased consciousness, vomiting, intestinal occlusion, undrained pneumothorax, and confusion and agitation states. Recent studies have shown that NIV can be successfully used in patients with hypercapnic coma (16) and after upper gastrointestinal surgery (17). The clinical setting is also important; if NIV is the ceiling of treatment and therefore the only treatment option, a relative contraindication can be accepted, whereas it may not be if intubation is considered appropriate. It is better, therefore, to consider these as situations requiring special care rather than contraindications per se. There are some situations, however, in which NIV is almost never appropriate, such as severe fixed upper airway obstruction requiring tracheostomy, and severe facial burns or trauma or anything that renders it impossible to fix an interface.

Non-invasive ventilation is complementary rather than an alternative to IMV, an intermediate level of support between no ventilatory support and IMV. The primary aim should be in general preventing progression of

ARF to the point at which patients will require intubation.

\section{Intensive care units}

The first RCT on the use of NIV in COPD exacerbations was conducted in an ICU (18). These patients had severe respiratory acidosis before inclusion into the study. Compared with standard medical treatment, the use of NIV decreased dramatically the need for intubation, with less incidence of complications, shorter hospital stay and lower hospital mortality. The benefits of NIV have been confirmed in several controlled trials in different countries (4). More-

Patients with good response to NIV had shorter ICU stay and better outcomes during the year after the hospitalization, with less readmission and less need of long-term oxygen therapy. over, no clinical study demonstrated that NIV is inferior to standard medical treatment.

In all these studies, patients deemed to need immediate intubation were excluded. A subsequent study on patients with COPD exacerbation that had failed standard medical treatment compared the use of NIV with immediate intubation (19). Therefore, these patients were substantially more severe that those included in previous studies, assessed by a mean arterial $\mathrm{pH}$ around 7.20 before randomisation. This study showed that NIV could avoid intubation in $48 \%$ patients and did not provide worse ventilatory support than IMV. Patients with good response to NIV had shorter ICU stay and better outcomes during the year alter the hospitalisation, with less readmission and less need of long-term oxygen therapy.

A more recent study compared 543 patients with COPD exacerbation and 173 patients with obesity-hypoventilation syndrome, admitted to an ICU for an episode of hypercapnic ARF. Despite their baseline severity of respiratory acidosis, with a mean arterial $\mathrm{pH} 7.22$, NIV was highly effective, with failure rates of $11 \%$ and $6 \%$ for patients with COPD and obesity-hypoventilation syndrome, respectively (20).

\section{Conventional wards}

Based in the evidence of successful use of NIV in the $\mathrm{ICU}$, the lack of need for pharmacologic sedation, and because NIV can be used earlier in the evolution of ARF before patients are considered to need intubation, several studies have assessed the use of NIV in conventional wards. The most relevant was a multicentre trial on COPD exacerbation that confirmed the efficacy of NIV in this setting (21). The early use of

The early use of NIV decreased the NIV failure rate and the hospital mortality, but NIV for mild acute respiratory failure isn't effective.
NIV together with standard treatment decreased the NIV failure rate and the hospital mortality compared with standard treatment alone. A subgroup analysis in patients with more severe acidosis, with baseline arterial $\mathrm{pH}<7.30$, showed 
no clinical benefits with an outcome worse than expected, suggesting that these patients with more severe acidosis should be managed in facilities with closed control and monitoring than that available in conventional wards. Conversely, in patients with very mild acidosis or no acidosis, NIV has not demonstrated any clinical benefit (22).

\section{Emergency room}

The emergency room is the first point of contact for many patients. In this setting, the main priority is optimizing medical treatment. Around 20\% patients with COPD exacerbation have initial respiratory acidosis,

The use of high-flow uncontrolled oxygen in ambulance for COPD exacerbation contributes to worsen outcomes compared to oxygen titration to achieve an arterial $\mathrm{O}_{2}$ saturation of $88-92 \%$. and in $20 \%$ of them arterial $\mathrm{pH}$ can be normalised by simply optimizing medical treatment (23), since hyperoxygenation is a common cause of hypercapnic acidosis. An australian study showed a higher mortality rate in COPD patients that received uncontrolled oxygen therapy in the ambulance compared with those in whom oxygen was titrated to achieve an arterial $\mathrm{O}_{2}$ saturation $\left(\mathrm{SaO}_{2}\right)$ of $88-92 \%$ (24). The use of high-flow oxygen contributes to increase the hospital length of stay,
ICU admission and the need for NIV when patients achieve higher levels of $\mathrm{SaO}_{2}$ (25). Therefore, patients with acidosis at arrival to the emergency room should receive oxygen with the aim to achieve $\mathrm{SaO}_{2}$ between 88 and $92 \%$ (26), in addition to medical treatment, including nebulised bronchodilators, steroids and antibiotics if indicated. If respiratory acidosis persists, NIV may be initiated in the emercency room with acceptable results as shown in a prospective study (27).

Figure 1 shows a simple algorithm proposed for taking decisions regarding NIV in COPD exacerbations.

\section{Non-invasive ventilation in hypoxemic acute respi- ratory failure}

The first problem in addressing patients with hypoxemic ARF is the heterogeneity of this condition. Studies assessing the outcome of patients with hypoxemic ARF treated with NIV in the ICU identified up to 9 different groups of patients, with substantial differences among them in the outcomes (Figure 2) (28). Moreover, a majority of clinical trials that assessed the efficacy of NIV in patients with hypoxemic ARF have studied mixed populations. The role of NIV in the management of patients with hypoxemic ARF from clinical trials with mixed and specific populations of patients will be discussed.

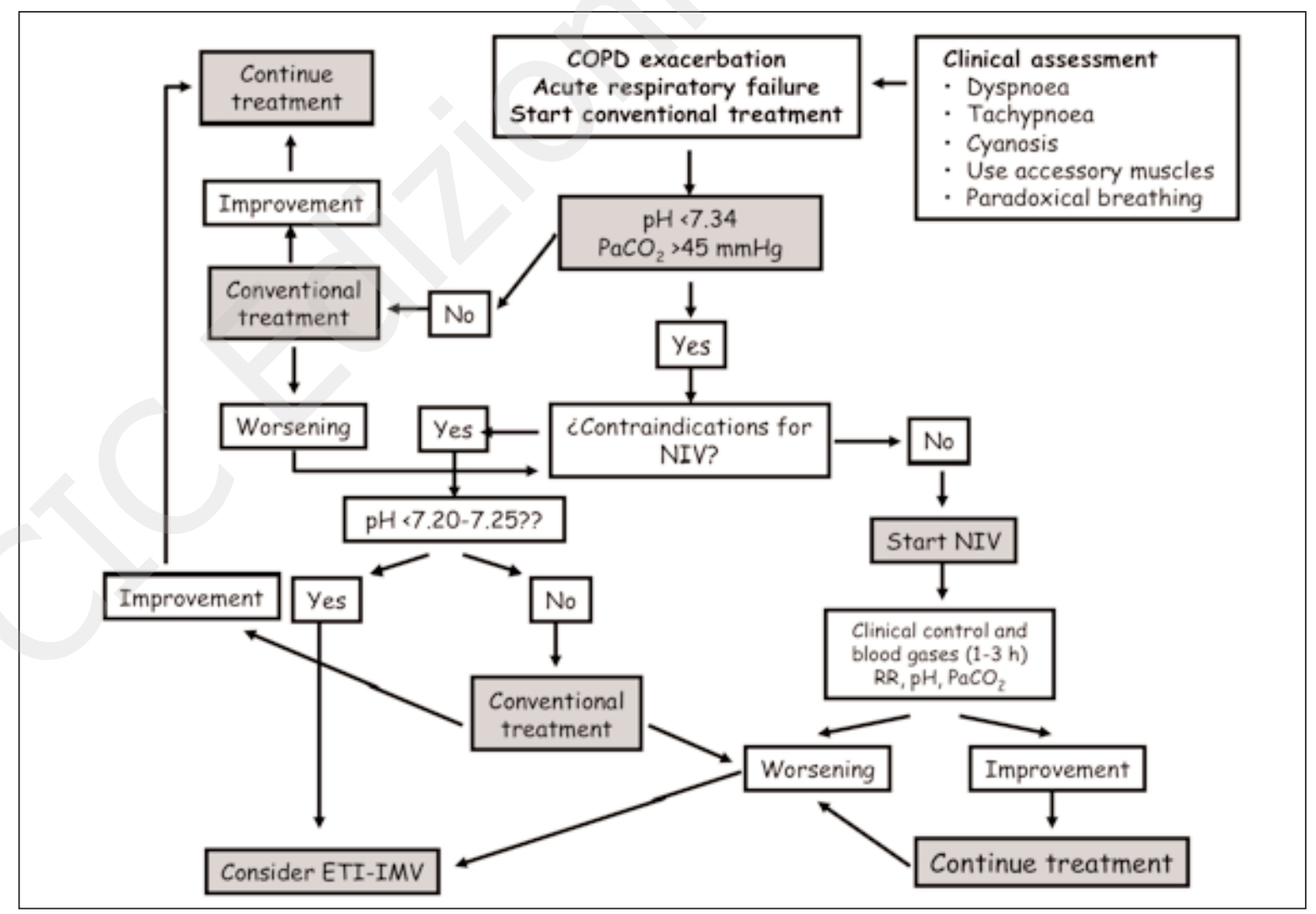

Figure 1 - Proposed algorithm for the institution of non-invasive ventilation in hypercapnic acute respiratory failure. 


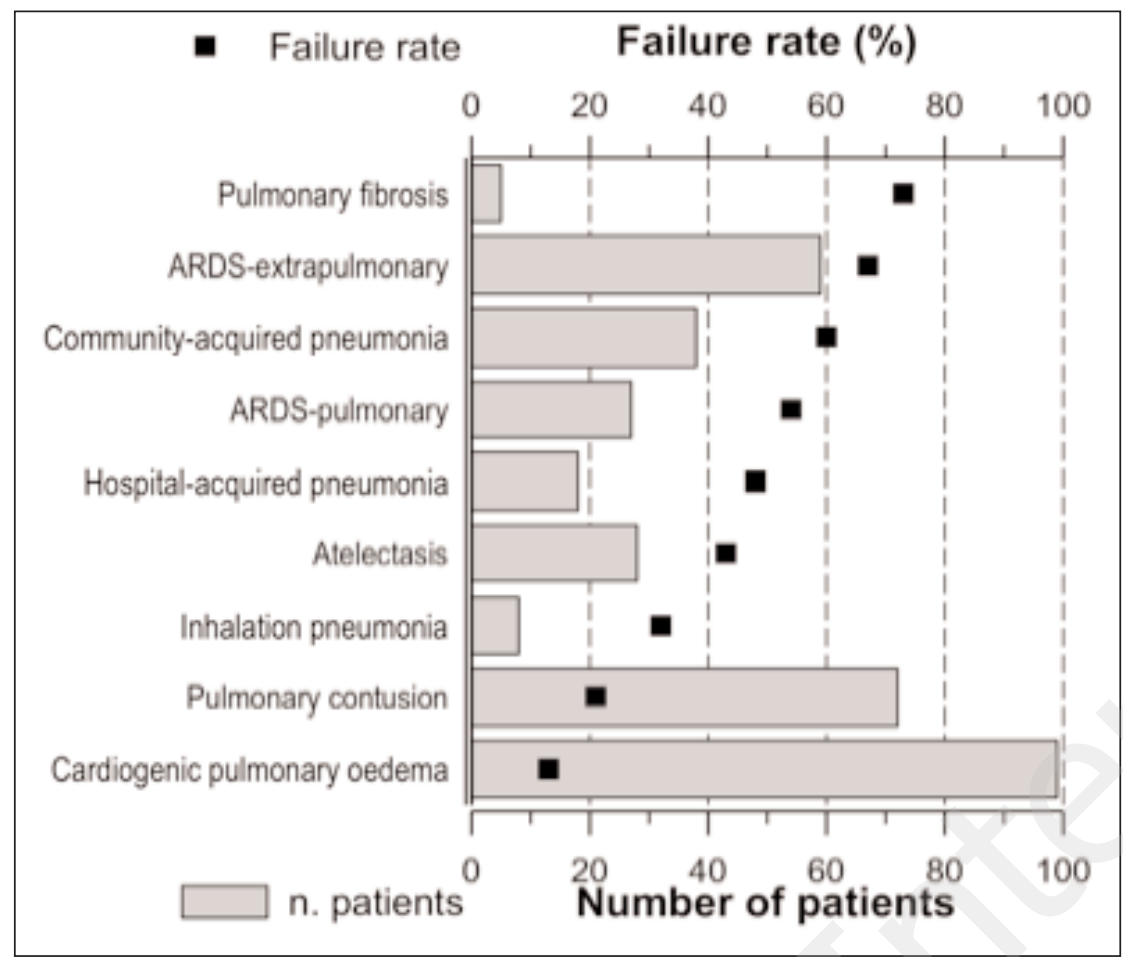

Figure 2 - Causes of acute hypoxemic respiratory failure and frequency of NIV failure. ARDS patients are divided into pulmonary and extra pulmonary origin. For each subset of patients, grey columns represent the number of patients, and the black dots represent the percentage of patients that required intubation. Adapted from (28).

\section{Severe community-acquired pneumonia}

The main objective of NIV in severe ARF is overcoming the acute episode without the need for intubation. However, pneumonia in patients treated with NIV is persistently associated with poor outcome in the literature, compared with other causes of ARF, both in patients with COPD exacerba-
In patients with severe hypoxemic ARF NIV may decrease the need for intubation and ICU mortality, with a faster improvement of arterial hypoxemia and tachypnea. tions (29) and in hypoxemic ARF (28). More recent studies have confirmed high failure rates in patients with pneumonia and severe ARF (27, 30-32). domised clinical trial (RCT) in the literature that compared conventional treatment with or without NIV gether with conventional treatment had lower rate of tracheal intubation and a shorter stay in the intermediate care unit than those who received conventional treatment only, although the length of hospital stay and hospital mortality were similar between both groups (33). This study also showed in a subset analysis that the significant benefits of NIV occurred in patients with COPD and hypercapnic respiratory failure only; this subset of patients had also a lower mortality after two months. In contrast, patients without COPD nor hypercapnic respiratory failure did not benefit from NIV. The better outcomes of NIV in patients with pneumonia and COPD and hypercapnia, compared with those with "de novo" ARF, have been recently highlighted (34).
The only prospective randemonstrated that patients who had received NIV to-
A more recent prospective RCT in patients with severe hypoxemic ARF demonstrated that NIV decreased the need for intubation and ICU mortality, with a faster improvement of arterial hypoxemia and tachypnea (Figure 3), compared with high-concentration oxygen therapy (35). A subgroup analysis showed that the benefits of NIV were restricted to patients with pneumonia as the cause of the episode of hypoxemic ARF.

\section{Acute respiratory distress syndrome}

Most observational studies and subgroup analyses of RCT show that patients with acute respiratory distress syndrome (ARDS) are among those with the worst outcome when they receive NIV as a support measure for severe hypoxemic ARF, with high rates of NIV failure $(28,30,35-38)$, and limited efficacy of NIV. The severity of arterial hypoxemia and the frequent impairment of pulmonary mechanics in these patients may explain the high intubation rate showed in several studies, regardless of NIV use or not.

The only published RCT on
In absence of criteria for immediate intubation, NIV could be tried in expert centres for patients with ARDS, avoiding its use in patients with predicted high mortality. in patients with mild ARDS according to the new Berlin definition (39). This study showed a decrease in the intubation rate and development of organ system dysfunctions, and a trend to decrease in-hospital mortality, with the use of NIV (40). One trial in more severe ARDS reported a significantly lower intubation rate with NIV in 84 patients with ARDS, but it was pub- 


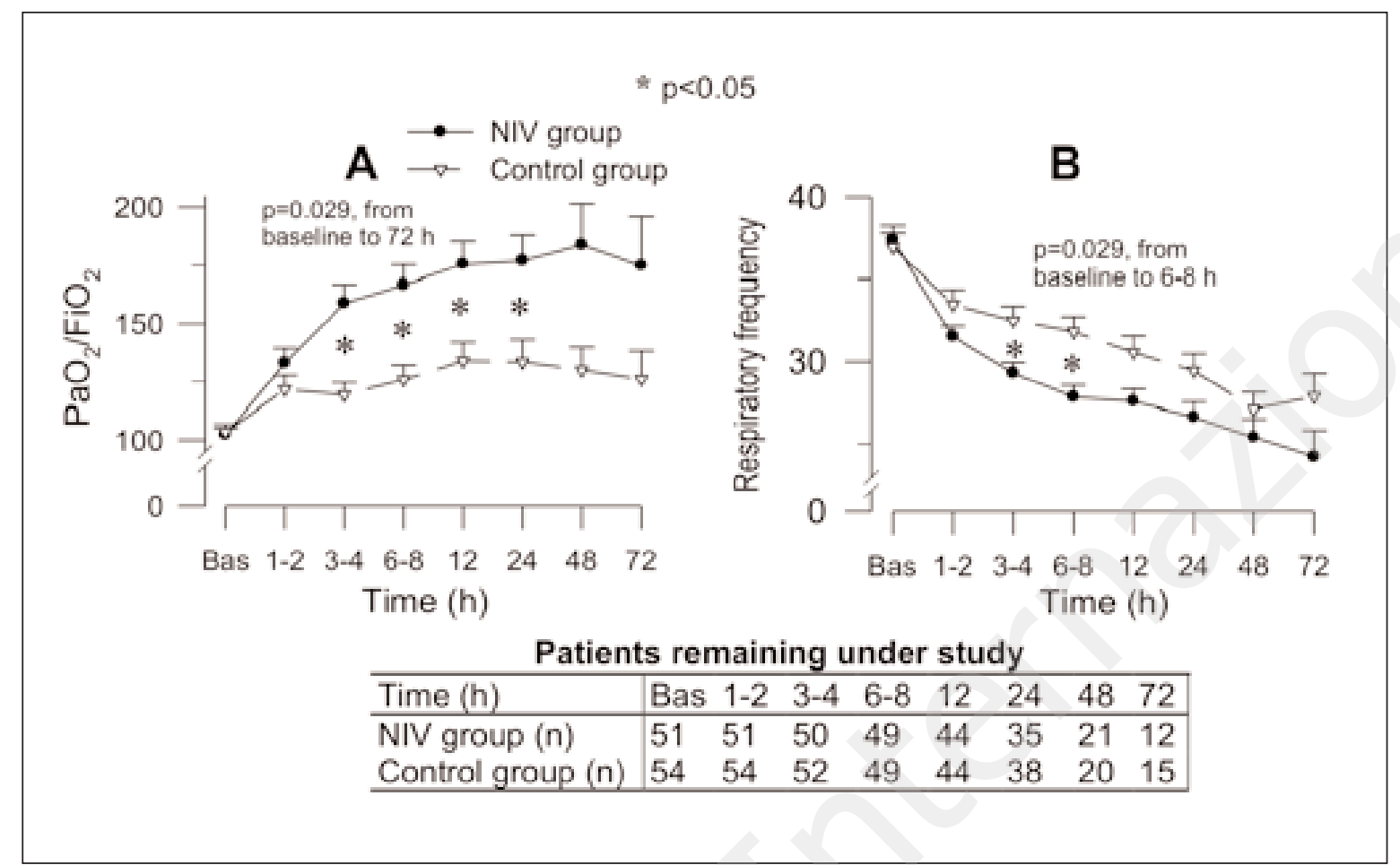

Figure 3 - Time-course evolution (mean \pm SEM) of arterial hypoxemia, as assessed by the $\mathrm{PaO}_{2} / \mathrm{FiO} 2$ ratio (panel A), and respiratory frequency (panel B), in the two groups. Both variables improved with time in the two groups. Asterisks denote significant differences between the two groups at individual time-points. After Bonferroni correction, the improvement of the two variables was significantly greater in the NIV group after 3-4 hours of randomization, and remained significantly greater 24 and 6-8 $\mathrm{h}$ after randomization for $\mathrm{PaO}_{2} / \mathrm{FiO}_{2}$ ratio and respiratory frequency, respectively. The table below the graph denotes the number of patients remaining under study at each time-point in the two groups. The time-course decrease of patients corresponds to those meeting criteria to terminate the protocol. Adapted from (35).

lished in abstract form only (41).

A prospective observational study in 54 patients with acute lung injury who received NIV found that shock, metabolic acidosis and profound hypoxemia predicted NIV failure (30). In this study, the observed mortality of patients who failed NIV was higher than that predicted by severity scores, suggesting that NIV should tried very cautiously, or not at all in patients with predictors of NIV failure, and particularly discouraged the use of NIV in those patients presenting with shock and metabolic acidosis. Another prospective multicenter cohort study showed that NIV as a first-line intervention improved hypoxemia and avoided intubation in $54 \%$ patients with early ARDS (42). In this study, higher severity scores and failure to improve hypoxemia after 1 hour of NIV were independently associated with NIV failure. This study suggested that, in absence of criteria for immediate intubation, NIV could be tried in expert centres for patients with ARDS, avoiding the use in patients with predicted high mortality. The authors recommended a close monitoring of arterial oxygenation and to proceed to rapid intubation when oxygenation in not rapidly improved after initiation of NIV. Overall, the risk-benefit ratio of NIV is still not defined in ARDS and current evidence does not support the routine use of NIV in these patients.
Other causes of severe hypoxemic acute respiratory failure

An important part of the first published series assessing the efficacy of NIV in patients with hypoxemic ARF included patients with different causes of ARF. These series could not establish the efficacy of NIV in this subset of patients and showed disparate results, mainly because of the own heterogeneity of hypoxemic ARF, since patients with CPO, ARDS and trauma were also included (43). Moreover, some of these initial studies observed a limited efficacy of NIV in patients with hypoxemic ARF of different origin, compared to patients with hypercapnic respiratory failure (44).

The first RCT specifically conducted in severely hypoxemic patients compared NIV with tracheal intubation in 64 with predefined criteria for initiating ventilatory support (45). Among patients who received NIV, only $31 \%$ required intubation. Likewise, the improvement in arterial oxygenation after the protocol was implemented was similar in patients from both groups, and the incidence of severe infectious complications was lower in patients who received NIV, with a trend to a lower ICU mortality and length of stay, compared with those who were initially intubated.

A more recent trial in patients with chest trauma re- 


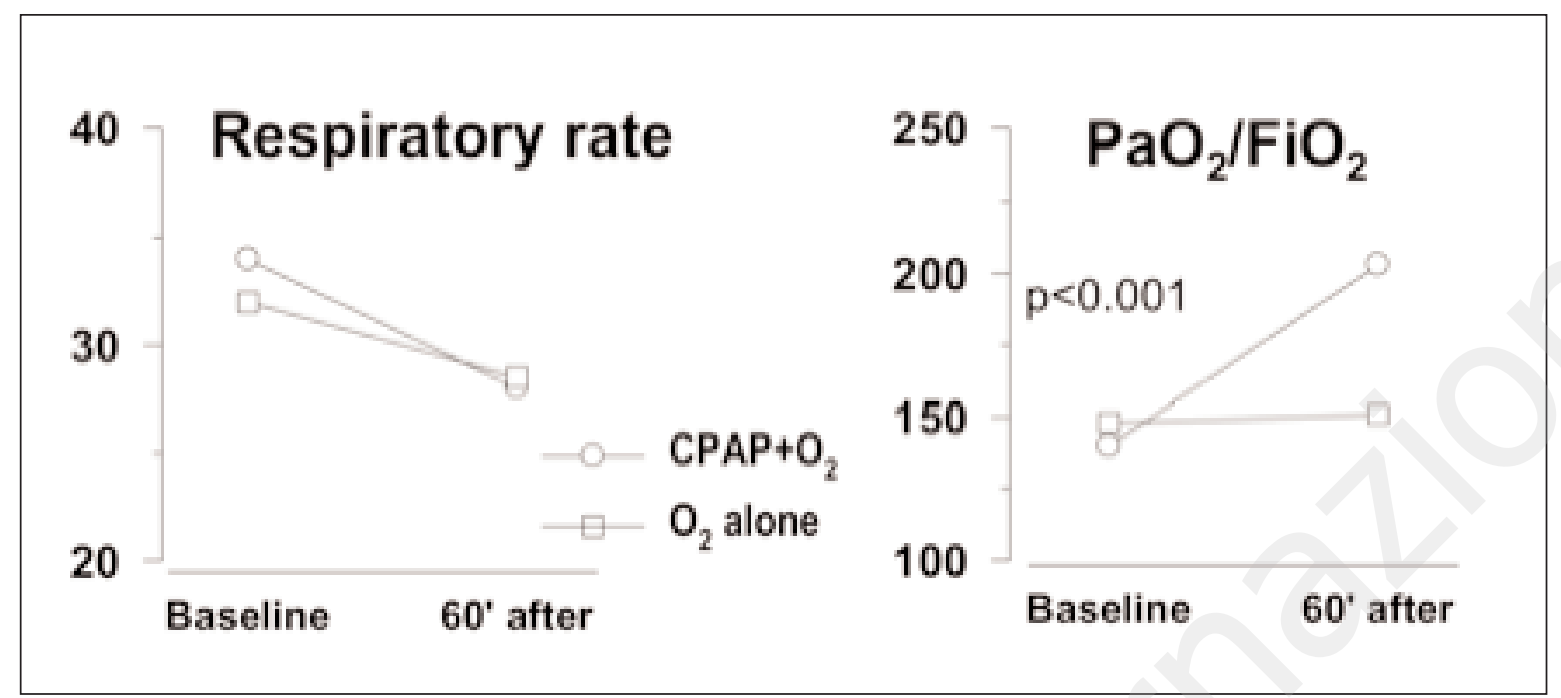

Figure 4 - Initial evolution of respiratory rate (left panel) and arterial hypoxemia, assessed by the arterial oxygen tension to inspired oxygen fraction ratio (right panel) for patients treated with CPAP plus oxygen as compared with those treated with oxygen alone, from baseline to $60 \mathrm{~min}$ after the initiation of treatment. Adapted from (47).

maining hypoxic despite regional anaesthesia showed that NIV reduced intubation compared with oxygen therapy in severe thoracic trauma related hypoxemia, with reduced length of hospital stay. However, mortality in this study was the same in both groups (46). In contrast, CPAP with face mask in patients with severe hypoxemic ARF improved hypoxemia, compared with oxygen therapy, but did not decrease the needs for tracheal intubation, hospital mortality and ICU length of stay (Figure 4) (47).

Physiologic effects of non-invasive ventilation in patients with hypoxemic acute respiratory failure The different clinical efficacy between NIV and CPAP may be explained by the results of a physiological study performed in 10 patients with severe hypoxemic ARF of different origin (48). Compared with spontaneous breathing, the respiratory frequency, the work of breathing and the respiratory drive improved only with NIV, whilst CPAP was more effective in improving. Since the most frequent indication for intubation in patients with hypoxemic ARF is exhaustion (35), it is necessary to combine NIV with PEEP in order to decrease the inspiratory effort, whilst CPAP improves arterial oxygenation but does not unload the respiratory muscles (Figure 5) (48).

\section{Failure of non-invasive ventilation: when to intu- bate?}

Concerns have been raised due to the high mortality rate of patients with hypoxemic ARF who fail NIV treatment (28). Particularly, failure of NIV was associated with ICU mortality in patients with hypoxemic ARF and without previous cardiac or respiratory disease ("de novo" ARF), but not in patients with acuteon-chronic respiratory failure or CPO in a prospective multicenter study (3). The possibility that unnecessary delay of intubation results in excess mortality in patients with acute lung injury was also highlighted in another prospective study that showed an actual mortality of patients intubated after NIV failure higher than mortality predicted by severity scores (30). However, these comparisons may be misleading, since severity scores often underestimate hospital mortality in ICU patients $(49,50)$. A more recent prospective study on the use of NIV in patients with CAP and severe ARF found for the first time a consistent association between delayed intubation and increased mortality in patients with CAP and "de
The optimal time for intubation after NIV failure remains a challenging issue due to increasing evidences on the relationship between delayed intubation and excess mortality in NIV failure patients. novo" ARF (34). In this study, a longer time on NIV before intubation was associated with less survival, even after adjustment for potential confounders such as severity scores and shock. A longer duration of NIV before intubation was not related with severity of patients at admission in this study. Therefore, this excess of mortality was attributed to delayed intubation rather than a more severely-ill selected population. By contrast, no relationship was found between delayed intubation and mortality in patients with CAP and previous cardiac or respiratory disease from this study (34).

In summary the RCTs of the literature suggest that patients with severe hypoxemic ARF have in general a lower likelihood to need tracheal intubation when NIV as a support for respiratory failure is added to the standard medical treatment. However, the effects of NIV on mortality are less evident, and the heterogeneity of the different published studies suggests that the 

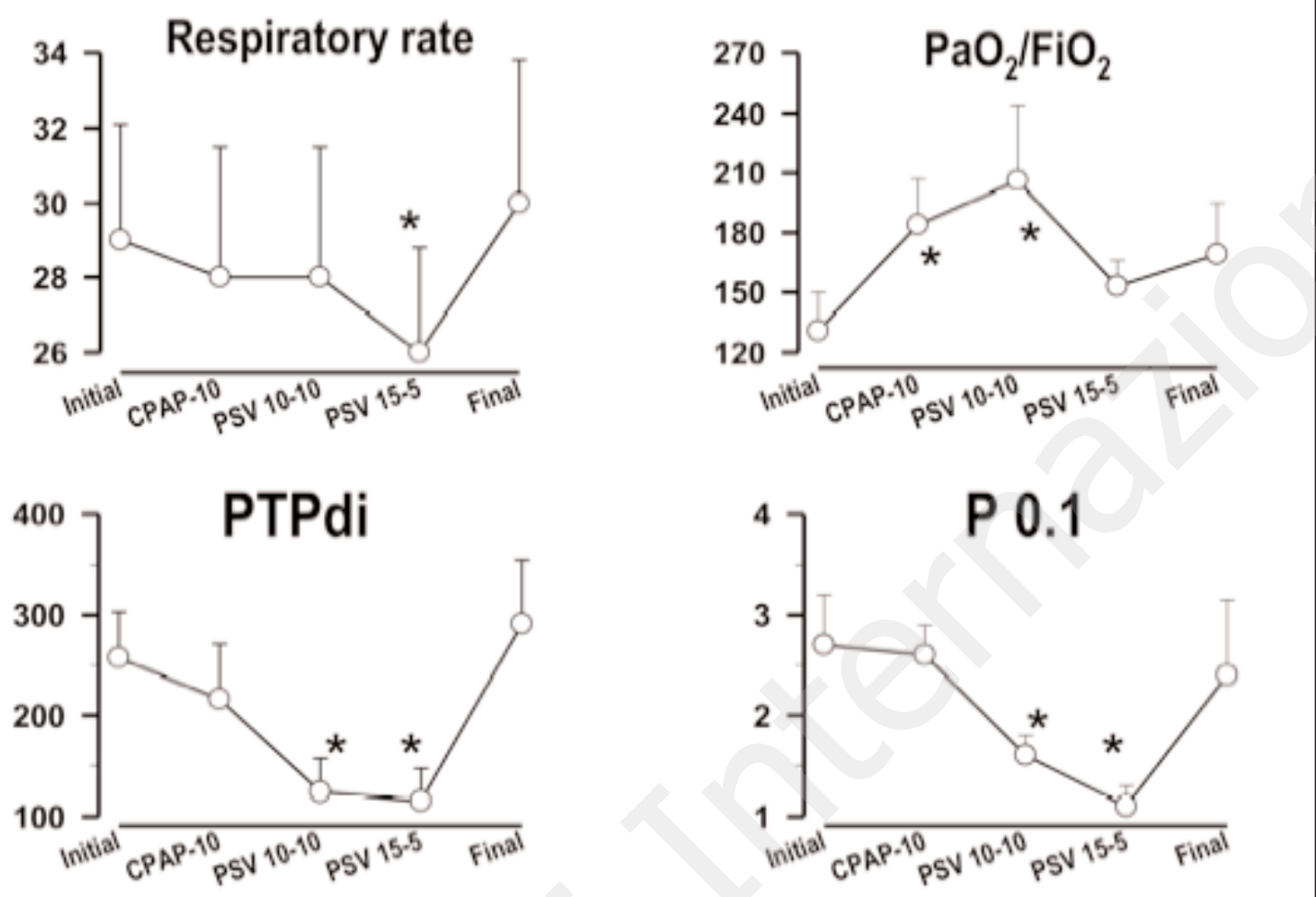

Figure 5 - Average changes in respiratory variables [respiratory frequency, arterial hypoxemia, assessed by the arterial oxygen tension to inspired oxygen fraction ratio, work of breathing, assessed by the pressure-time product of the diaphragm (PTPdi), and the respiratory drive, assessed by the occlusion pressure $\left(\mathrm{P}_{0.1}\right)$ ] comparing the initial and final values during spontaneous breathing with the three ventilatory modalities: CPAP $10 \mathrm{cmH}_{2} \mathrm{O}$, pressure-support ventilation (PSV) $10 \mathrm{cmH}$ with PEEP $10 \mathrm{cmH}_{2} \mathrm{O}$, and PSV $15 \mathrm{cmH}_{2} \mathrm{O}$ with PEEP $5 \mathrm{cmH}_{2} \mathrm{O}$. Asterisks denote significant differences between initial values and the specific ventilatory modality. Adapted from (48).

efficacy may be different among different populations. The optimal time for intubation after NIV failure remains a challenging issue due to increasing evidences on the relationship between delayed intubation and excess mortality in these populations.

\section{Non-invasive ventilation in withdrawal from me-} chanical ventilation

An International Consensus Conference on weaning from MV (51) proposed a new classification based on the difficulty and duration of the weaning period: 1) simple weaning; 2) difficult weaning; and 3) prolonged weaning. Patients with chronic airflow obstruction and difficult or prolonged weaning are at increased risk for prolonged IMV. Non-invasive ventilation has been used in different indications during withdrawal of mechanical ventilation: 1) to advance extubation in patients with difficult or prolonged weaning; 2) to avoid re-intubation in patients who have developed post-extubation respiratory failure; and 3) to prevent the development of post-extubation respiratory failure. The role of NIV in all these indications will be reviewed.

\section{Pathophysiologic mechanisms of difficult and pro-} longed weaning (Table 1)

Patients with unsuccessful weaning from mechanical ventilation are likely to develop during a spontaneous breathing trial a rapid and shallow breathing pattern (52), with progressive worsening of dynamic lung elastance, intrinsic PEEP (PEEPi), inspiratory resistance, and work of breathing (53). All these changes are not present when patients successfully tolerate a spontaneous breathing trial.

In COPD patients, an inappropriate cardiovascular response to the switch from positive-pressure ventilation to spontaneous breathing with left ventricular dysfunction and increased pulmonary artery occlusion pressure may also occur during weaning failure $(54,55)$, with decreased mixed venous oxygen saturation (56), reflecting the inability of the cardiovascular system to compensate the increased systemic oxygen demands when spontaneous breathing is instituted. Conversely, in successfully weaned patients, mixed venous oxygen tension or saturation was shown to remain unchanged or increased during spontaneous breathing, compared with positive pressure ventilation (56-58). 
Table 1 - Pathophysiologic bases of weaning failure during transition from positive-pressure ventilation to spontaneous breathing.

\begin{tabular}{l}
\hline - Rapid and shallow breathing pattern \\
\hline - Increased workload of the respiratory muscles: \\
Increased PEEPi \\
Increased elastance and resistance of the respiratory \\
system \\
Increased work of breathing \\
Increased effective inspiratory impedance \\
Increased load/capacity balance \\
\hline Inappropriate cardiovascular response \\
Increased venous return to right ventricle \\
Increased negative deflections in intrathoracic pressure \\
Increased left ventricular afterload \\
Fall of mixed venous $\mathrm{P}_{\mathrm{v}} \mathrm{O}_{2}$ and $\mathrm{SvO}_{2}$
\end{tabular}

- Impaired neurological status

Definitions of abbreviations: $\mathrm{PEEPi}=$ intrinsic positive endexpiratory pressure; $\mathrm{PvO}_{2}=$ mixed venous oxygen tension; $\mathrm{SvO}_{2}=$ mixed venous oxygen saturation .

Rationale for the use of non-invasive ventilation during difficult and prolonged weaning (Table 2) In COPD patients, the rationale for using NIV in facilitating weaning may be related to the ability of NIV to reduce the work of breathing (59), with an additive effect of both positive pressure ventilation and external PEEP. The short-term improvement of hypoxemia and hypercapnia with NIV in these patients appear to be related to increased alveolar ventilation secondary to attainment of a slower and deeper breathing pattern, with no changes in the ventilation-perfusion mismatch (60). The same beneficial effects have been demonstrated in ventilator-dependent patients with chronic respiratory disorders, with similar efficacy of pressure-support ventilation delivered through the endotracheal tube and non-invasively after extubation in reducing the work of breathing and improving arterial blood gases and respiratory pattern (61).

Table 2 - Physiologic effects of non-invasive positive-pressure ventilation.

- Effect on respyratory mechanics

Decrease negative deflections of intrathoracic pressure

Decreased work of breathing

Additive effects of positive pressure ventilation and external PEEP

- Effects on gas exchange

Improvement of hypoxemia and hypercapnia secondary to slower and deeper breathing pattern

No effects on ventilation-perfusion mismatch

Definitions of abbreviations: PEEP = positive end-expiratory pressure.

The use of non-invasive ventilation during difficult and prolonged weaning

Shortening weaning and avoiding re-intubation should be the primary end-point when NIV is indicated in patients with unsuccessful weaning from mechanical ventilation, as stated in an International Consensus Conference (62).

A RCT conducted in a selected group of 50 intubated COPD patients with severe hypercapnic respiratory

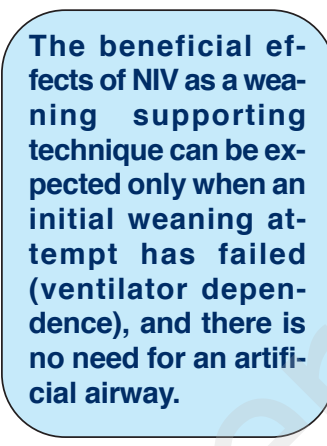

failure who had recovered

from of an exacerbation within $48 \mathrm{~h}$ of mechanical ventilation but had failed a spontaneous breathing trial with a T-piece showed that early extubation with NIV support resulted in shorter duration of mechanical ventilation and ICU stay, a lower incidence of nosocomial pneumonia and improved survival (63).

In a similar population of 33 intubated patients with acute-on-chronic respiratory failure after a single weaning trial failure with hypercapnic respiratory failure, extubation with NIV permitted a reduction of the endotracheal mechanical ventilation period of 3 days in average (64).

The effect of NIV during prolonged weaning was assessed in 43 mixed patients, predominantly with chronic respiratory disorders, that had failed a spontaneous breathing trial for 3 consecutive days (65). In this study, advancing extubation with NIV resulted again in a decreased duration of mechanical ventilation and stay, lower incidence of incidence of nosocomial pneumonia and septic shock/multiple organ failure, less need of tracheotomy to facilitate weaning, and improvement in survival.

The use of mechanically-assisted cough in addition to NIV has been recently described in 157 consecutive "unweanable" intubated patients with neuromuscular disease (66). This study showed that continuous volume-cycled NIV via oral interfaces and masks and mechanically-assisted cough permitted safe extubation in $95 \%$ of cases after the first attempt, with additional success on subsequent attempts in some additional patients.

A systematic review and meta-analysis on the use of NIV to wean critically-ill adult patients off mechanical ventilation identified several additional RCTs published or presented as abstracts (67). This study showed a consistent positive effect of NIV on mortality and ventilator-associated pneumonia, though the net clinical benefits remain to be fully elucidated (Table 3 ). This study also recommended that NIV should preferentially be used in patients with COPD in a highly monitored environment. This emphasis in COPD as the population most prone to benefit from NIV in facilitating difficult and prolonged weaning has been recently suggested (68).

However, all these studies, and the conclusions drawn from them, are related to selected populations of patients with underlying chronic airflow obstruction and 
Table 3 - Summary estimates of the effect of non-invasive ventilation to wean critically ill adults off invasive ventilation. Adapted from (67).

\begin{tabular}{lll}
\hline Outcome & Summary estimate $\mathbf{( 9 5 \%} \mathbf{C l})$ & P value \\
\hline Mortality * & $0.55(0.38$ to 0.79$)$ & 0.001 \\
VAP * & $0.29(0.19$ to 0.45$)$ & $<0.001$ \\
Weaning failures * & $0.72(0.37$ to 1.42$)$ & 0.34 \\
Length of stay: & & $<0.001$ \\
Intensive care $\dagger$ & $-6.3(-8.8$ to -3.8$)$ & $<0.001$ \\
Hospital $\dagger$ & $-7.2(-10.8$ to -3.6$)$ & \\
Duration of mechanical ventilation: & & 0.004 \\
$\quad$ Total $\dagger$ & $-5.6(-9.5$ to -1.8$)$ & 0.42 \\
Related to weaning $\dagger$ & $-0.9(-3.2$ to 1.4$)$ & $<0.001$ \\
Endotracheal $\dagger$ & $-7.8(-11.3$ to -4.3$)$ & \\
Adverse effects: & & 0.31 \\
Re-intubation * & $0.73(0.40$ to 1.34$)$ & 0.020 \\
Tracheostomy * & $0.16(0.04$ to 0.75$)$ & 0.96 \\
Arrhythmia * & $1.05(0.17$ to 6.67$)$ & \\
\hline Abbrevations: & & \\
\hline
\end{tabular}

Abbreviations: $V A P=$ ventilator associated pneumonia; $\mathrm{Cl}=$ confidence interval.

${ }^{*}$ Relative risk. + Weighted mean difference.

hypercapnic respiratory failure, hemodynamic stability, normal consciousness, absence of fever, and preserved cough reflex. Moreover, the $12 \mathrm{RCTs}$ identified in a recent systematic review included a total of 530 patients; however, only 3 of these trials, with 126 patients included, were published in high quartile peerreview journals (67).

Because it must be distinguished between dependence from the ventilator and from the endotracheal intubation, when the process of mechanical ventilation withdrawal is initiated, it is necessary to evaluate: 1) the need of ventilatory support with a spontaneous breathing trial; and 2) whether the artificial airway is needed or not. The beneficial effects of NIV as a weaning supporting technique can be expected only when an initial weaning attempt has failed (ventilator dependence) but there is no need for an artificial airway. The main reasons for failure of NIV are the lack of co-operation, excessive secretions, severe strengthload imbalance and hemodynamic instability, which can be corrected by protection of the airways and proper medical therapy. In general, it is estimated that around $30-35 \%$ of intubated COPD patients with hypercapnic respiratory failure needing progressive withdrawal of mechanical ventilation are not likely to benefit from NIV, but large-scale studies are needed to confirm these estimations.

\section{Respiratory failure after extubation}

Re-intubation, which occurs in 6 to $23 \%$ cases within 48 to 72 hours after planned extubation (69-71), is a relevant consequence of respiratory failure after extubation (72). Although the need for re-intubation may be a marker of increased severity of illness, this is an independent risk factor for nosocomial pneumonia (73), and mortality and increased hospital stay (69). Therefore, in addition to an accurate prediction of extubation outcome, strategies for preventing the development of respiratory failure after extubation and subsequent re-intubation are needed.

\section{Non-invasive ventilation in the management of} respiratory failure after extubation

The clinical benefits of NIV in the management of patients who have been extubated but have developed respiratory failure after extubation are not encouraging. Two RCTs on the use of NIV in the treatment of respiratory failure after extubation did not show benefits from NIV in avoiding re-intubation $(72,74)$. The first trial selected 81 patients with different underlying diseases, and did not find
If the use of NIV after extubation prolongs time to re-intubation, then NIV may become an independent risk factor for mortality in re-intubated patients. any benefit from NIV in terms of re-intubation, duration of mechanical ventilation and stay, and survival (74). More recently, a multi-centre international RCT in 221 patients who develop respiratory failure after extubation found again no benefits for NIV in reducing re-intubation and length of stay (72). The striking point of this study was a higher ICU mortality in patients treated with NIV, attributed to a longer period of time from extubation to re-intubation in patients treated with NIV, which is an independent risk factor for mortality in reintubated patients (75). In both trials, the proportion of COPD patients was low, $10 \%$ and $11 \%$. 


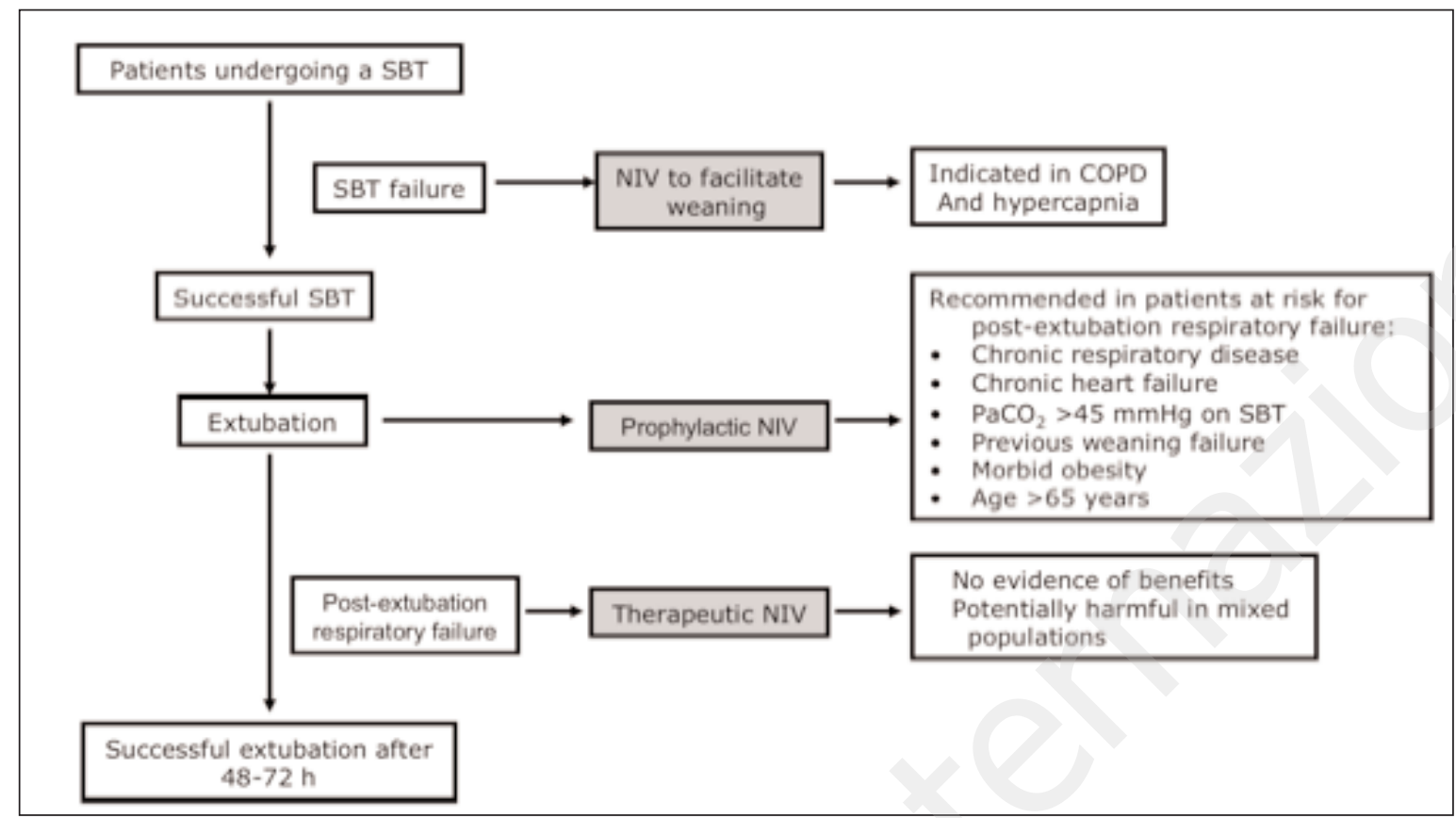

Figure 6 - Schematic representation of the application of non-invasive ventilation (NIV) during the different phases of ventilator withdrawal. SBT = spontaneous breathing trial; COPD = chronic obstructive pulmonary disease. Adapted from (68).

\section{Non-invasive ventilation in the prevention of respi- ratory failure after extubation}

Since NIV seems not effective to avert re-intubation once patients have developed respiratory failure after extubation, a strategy based on the early use of NIV during the initial periods after extubation in order to avert respiratory failure after extubation in patients at risk for this complication seems more appropriate.

Several RCTs have used this approach with favourable results. In selected patients at increased risk to develop respiratory failure after extubation, the early use of NIV after a successful weaning trial was compared with a conventional approach using oxygen therapy $(76,77)$. In both studies, the use of NIV resulted in decreased incidence of extubation failure and reintubation, with a strong association between the need for re-intubation and mortality. A subgroup analysis in one of these studies found in improvement in survival only in patients with hypercapnia during the spontaneous breathing trial (77). After these findings, the same group conducted a new RCT specifically in patients with chronic respiratory disorders and hypercap-

The early use of NIV
as weaning method
in intubated COPD
patients who failed
a previous NIV trial
is effective to reduce
the duration of me-
chanical ventilation
and its complica-
tions.
nia during a successful spontaneous breathing trial, with the same study design (78). The results from this study confirm again that the use of NIV immediately after extubation results in decreased incidence of respiratory failure after extubation and improved survival. The benefits of NIV in the prevention of respiratory failure after extubation were also documented in severely obese patients in a casecontrol study (79). In this study, the benefits in survival were also restricted in hypercapnic patients only. More recently, a multicentre RCT in difficult-to-wean patients with chronic hypercapnic respiratory failure investigated the effectiveness of NIV as an early weaning and extubation technique (80). The weaning failure rate in this study was significantly lower for patients extubated with NIV, compared with patients extubated without ventilatory support or those who remained intubated with a conventional weaning.

In summary, NIV is consistently effective in advancing extubation and decreasing complications associated with prolonged invasive ventilation in intubated patients with chronic respiratory disorders and difficult or prolonged weaning. There are also evidences on the efficacy of early use of NIV in preventing extubation failure and improving outcome in patients with chronic respiratory or cardiac diseases who present with hypercapnic respiratory failure during a spontaneous breathing trial. A very recent report has confirmed that such population is at high risk for extubation failure and subsequent pneumonia and death (81). A schematic representation of the application of NIV during the different phases of ventilator withdrawal is shown in Figure 6.

\section{References}

1. Girou E, Schortgen F, Delclaux C, et al. Association of noninvasive ventilation with nosocomial infections 
and survival in critically ill patients. JAMA. 2000; 284:2361-67.

2. Meade MO, Cook DJ, Kernerman P, Bernard G. How to use articles about harm: the relationship between high tidal volumes, ventilating pressures, and ventilator-induced lung injury. Crit Care Med. 1997;25: 1915-22.

3. Demoule A, Girou E, Richard JC, Taille S, Brochard L. Benefits and risks of success or failure of noninvasive ventilation. Intensive Care Med. 2006;32: 1756-65.

4. Ram FS, Picot J, Lightowler J, Wedzicha JA. Non-invasive positive pressure ventilation for treatment of respiratory failure due to exacerbations of chronic obstructive pulmonary disease. Cochrane Database Syst Rev. 2004;CD004104

5. Nava S, Hill N. Non-invasive ventilation in acute respiratory failure. Lancet. 2009;374:250-259.

6. Weng CL, Zhao YT, Liu QH, et al. Meta-analysis: Noninvasive ventilation in acute cardiogenic pulmonary edema. Ann Intern Med. 2010;152:590-600.

7. Antonelli M, Conti G, Bufi M, et al. Noninvasive ventilation for treatment of acute respiratory failure in patients undergoing solid organ transplantation. JAMA. 2000;283:235-41.

8. Hilbert G, Gruson D, Vargas F, et al. Noninvasive ventilation in immunosuppressed patients with pulmonary infiltrates, fever, and acute respiratory failure. N Engl J Med. 2001;344:481-87.

9. Keenan SP, Sinuff T, Cook DJ, Hill NS. Does noninvasive positive pressure ventilation improve outcome in acute hypoxemic respiratory failure? A systematic review. Crit Care Med. 2004;32:2516-23.

10. Keenan SP, Sinuff T, Burns KE, et al. Clinical practice guidelines for the use of noninvasive positivepressure ventilation and noninvasive continuous positive airway pressure in the acute care setting. CMAJ. 2011;183:E195-E214.

11. Garcia-Aymerich J, Monso E, Marrades RM et al. Risk factors for hospitalization for a chronic obstructive pulmonary disease exacerbation. EFRAM study. Am J Respir Crit Care Med. 2001;164:1002-7.

12. Celli BR, Barnes PJ. Exacerbations of chronic obstructive pulmonary disease. Eur Respir J. 2007; 29:1224-38.

13. Donaldson GC, Seemungal TA, Bhowmik A, Wedzicha JA. Relationship between exacerbation frequency and lung function decline in chronic obstructive pulmonary disease. Thorax. 2002;57:84752.

14. Seemungal TA, Donaldson GC, Paul EA, Bestall JC, Jeffries DJ, Wedzicha JA. Effect of exacerbation on quality of life in patients with chronic obstructive pulmonary disease. Am J Respir Crit Care Med. 1998; 157:1418-22.

15. Roberts CM, Lowe D, Bucknall CE, Ryland I, Kelly Y, Pearson MG. Clinical audit indicators of outcome following admission to hospital with acute exacerbation of chronic obstructive pulmonary disease. Thorax. 2002;57:137-41.

16. Gonzalez Diaz G, Carrillo Alcaraz A, Pardo Talavera $\mathrm{JC}$, et al. Noninvasive positive-pressure ventilation to treat hypercapnic coma secondary to respiratory failure. Chest. 2005;127:952-60.

17. Michelet P, D'Journo XB, Seinaye F, Forel JM, Papazian $L$, Thomas $P$. Non-invasive ventilation for treatment of postoperative respiratory failure after oesophagectomy. Br J Surg. 2009;96:54-60.

18. Brochard L, Mancebo J, Wysocki M, et al. Noninvasive ventilation for acute exacerbations of chronic obstructive pulmonary disease. N Engl J Med. 1995; 333:817-22.

19. Conti G, Antonelli M, Navalesi P, et al. Noninvasive vs. conventional mechanical ventilation in patients with chronic obstructive pulmonary disease after failure of medical treatment in the ward: a randomized trial. Intensive Care Med. 2002;28:1701-7.

20. Carrillo A, Ferrer M, Gonzalez-Diaz G, et al. Noninvasive ventilation in acute hypercapnic respiratory failure caused by obesity hypoventilation syndrome and chronic obstructive pulmonary disease. Am J Respir Crit Care Med. 2012;186:1279-85.

21. Plant PK, Owen JL, Elliott MW. Early use of non-invasive ventilation for acute exacerbations of chronic obstructive pulmonary disease on general respiratory wards: a multicentre randomised controlled trial. Lancet. 2000;355:1931-35.

22. Barbe F, Togores B, Rubi M, Pons S, Maimo A, Agusti AG. Noninvasive ventilatory support does not facilitate recovery from acute respiratory failure in chronic obstructive pulmonary disease. Eur Respir J. 1996;9:1240-1245.

23. Plant PK, Owen JL, Elliott MW. One year period prevalence study of respiratory acidosis in acute exacerbations of COPD: implications for the provision of non-invasive ventilation and oxygen administration. Thorax. 2000;55:550-554.

24. Austin MA, Wills KE, Blizzard L, Walters EH, WoodBaker R. Effect of high flow oxygen on mortality in chronic obstructive pulmonary disease patients in prehospital setting: randomised controlled trial. BMJ. 2010;341:c5462.

25. Joosten SA, Koh MS, Bu X, Smallwood D, Irving LB. The effects of oxygen therapy in patients presenting to an emergency department with exacerbation of chronic obstructive pulmonary disease. Med J Aust. 2007; 186:235-38.

26. O'Driscoll BR, Howard LS, Davison AG. BTS guideline for emergency oxygen use in adult patients. Thorax. 2008;63 Suppl 6:vi1-68.

27. Antro C, Merico F, Urbino R, Gai V. Non-invasive ventilation as a first-line treatment for acute respiratory failure: "real life" experience in the emergency department. Emerg Med J. 2005;22:772-77.

28. Antonelli M, Conti G, Moro ML, et al. Predictors of failure of noninvasive positive pressure ventilation in patients with acute hypoxemic respiratory failure: a multi-center study. Intensive Care Med. 2001; 27:1718-28.

29. Ambrosino N, Foglio K, Rubini F, Clini E, Nava S, Vitacca M. Non-invasive mechanical ventilation in acute respiratory failure due to chronic obstructive pulmonary disease: correlates for success. Thorax. 1995;50:755-57. 
30. Rana S, Jenad H, Gay PC, Buck CF, Hubmayr RD, Gajic O. Failure of non-invasive ventilation in patients with acute lung injury: observational cohort study. Crit Care. 2006;10:R79.

31. Honrubia T, Garcia Lopez FJ, Franco N, et al. Noninvasive vs conventional mechanical ventilation in acute respiratory failure: a multicenter, randomized controlled trial. Chest. 2005;128:3916-24.

32. Carron M, Freo U, Zorzi M, Ori C. Predictors of failure of noninvasive ventilation in patients with severe community-acquired pneumonia. J Crit Care. 2010;25:540.e9-540.e14.

33. Confalonieri M, Potena A, Carbone G, Della Porta R, Tolley $\mathrm{E}$, Meduri $\mathrm{G}$. Acute respiratory failure in patients with severe community-acquired pneumonia. A prospective randomized evaluation of noninvasive ventilation. Am J Respir Crit Care Med. 1999;160: 1585-91.

34. Carrillo A, Gonzalez-Diaz G, Ferrer M, et al. Non-invasive ventilation in community-acquired pneumonia and severe acute respiratory failure. Intensive Care Med. 2012;38:458-66.

35. Ferrer M, Esquinas A, Leon M, Gonzalez G, Alarcon A, Torres A. Noninvasive ventilation in severe hypoxemic respiratory failure: A randomized clinical trial. Am J Respir Crit Care Med. 2003;168:1438-44.

36. Adda M, Coquet I, Darmon M, Thiery G, Schlemmer $\mathrm{B}$, Azoulay $\mathrm{E}$. Predictors of noninvasive ventilation failure in patients with hematologic malignancy and acute respiratory failure. Crit Care Med. 2008; 36:2766-72.

37. Gristina GR, Antonelli M, Conti G, et al. Noninvasive versus invasive ventilation for acute respiratory failure in patients with hematologic malignancies: a 5year multicenter observational survey. Crit Care Med. 2011;39:2232-39.

38. Agarwal R, Aggarwal AN, Gupta D. Role of noninvasive ventilation in acute lung injury/acute respiratory distress syndrome: a proportion meta-analysis. Respir Care. 2010;55:1653-60.

39. Ranieri VM, Rubenfeld GD, Thompson BT, et al. Acute respiratory distress syndrome: the Berlin Definition. JAMA. 2012;307:2526-33.

40. Zhan Q, Sun B, Liang L, et al. Early use of noninvasive positive pressure ventilation for acute lung injury: a multicenter randomized controlled trial. Crit Care Med. 2012;40:455-60.

41. Guisset O, Gruson D, Vargas F, Gabinski C, GbikpiBenissan G, Guenard H, Hilbert G. Non-invasive ventilation (NIV) in acute respiratory distress syndrome (ARDS) patients. Intensive Care Med. 2003;29 (Suppl. 1), S124. Ref Type: Abstract

42. Antonelli M, Conti G, Esquinas A, et al. A multiplecenter survey on the use in clinical practice of noninvasive ventilation as a first-line intervention for acute respiratory distress syndrome. Crit Care Med. 2007;35:18-25.

43. Meduri G, Turner R, Abou-Shala N, Wunderink RG, Tolley E. Noninvasive positive pressure ventilation via face mask. First-line intervention in patients with acute hypercapnic and hypoxemic respiratory failure. Chest. 1996;109:179-93.
44. Wysocki M, Tric L, Wolff MA, Millet H, Herman B. Noninvasive pressure support ventilation in patients with acute respiratory failure: a randomized comparison with conventional therapy. Chest. 1995; 107:761-68.

45. Antonelli M, Conti G, Rocco M, et al. A comparison of noninvasive positive-pressure ventilation and conventional mechanical ventilation in patients with acute respiratory failure. N Engl J Med. 1998;339: 429-35.

46. Hernandez G, Fernandez R, Lopez-Reina P, et al. Noninvasive ventilation reduces intubation in chest trauma-related hypoxemia: a randomized clinical trial. Chest. 2010;137:74-80.

47. Delclaux C, L'Her E, Alberti C, et al. Treatment of acute hypoxemic nonhypercapnic respiratory insufficiency with continuous positive airway pressure delivered by a face mask: a randomized controlled trial. JAMA. 2000;284:2352-60.

48. L'Her E, Deye N, Lellouche F, et al. Physiologic effects of noninvasive ventilation during acute lung injury. Am J Respir Crit Care Med. 2005;172:1112-18.

49. Goldhill DR, Sumner A. Outcome of intensive care patients in a group of British intensive care units. Crit Care Med. 1998;26:1337-45.

50. Goldhill DR, Withington PS. The effect of casemix adjustment on mortality as predicted by APACHE II. Intensive Care Med. 1996;22:415-19.

51. Boles JM, Bion J, Connors A, et al. Weaning from mechanical ventilation. Eur Respir J. 2007;29:1033-56.

52. Tobin MJ, Perez W, Guenther SM, et al. The pattern of breathing during successful and unsuccessful trials of weaning from mechanical ventilation. Am Rev Respir Dis. 1986;134:1111-18.

53. Jubran A, Tobin MJ. Pathophysiologic basis of acute respiratory distress in patients who fail a trial of weaning from mechanical ventilation. Am J Respir Crit Care Med. 1997;155:906-15.

54. Lemaire F, Teboul J, Cinotti L, et al. Acute left ventricular dysfunction during unsuccessful weaning from mechanical ventilation. Anesthesiology. 1988;69:17179.

55. Richard Ch, Teboul JL, Archambaud F, Hebert JL, Michaut P, Auzepy P. Left ventricular function during weaning of patients with chronic obstructive pulmonary disease. Intensive Care Med. 1994;20:18186.

56. Jubran A, Mathru M, Dries D, Tobin MJ. Continuous recordings of mixed venous oxygen saturation during weaning from mechanical ventilation and the ramifications thereof. Am J Respir Crit Care Med. 1998;158:1763-69.

57. Torres A, Reyes A, Roca J, Wagner PD, RodriguezRoisin R. Ventilation-perfusion mismatching in chronic obstructive pulmonary disease during ventilator weaning. Am Rev Respir Dis. 1989;140:124650.

58. Ferrer M, Iglesia R, Roca J, Burgos F, Torres A, Rodriguez-Roisin $R$. Pulmonary gas exchange response to weaning with pressure-support ventilation in exacerbated COPD patients. Intensive Care Med. 2002;28:1595-99. 
59. Appendini L, Patessio A, Zanaboni S, et al. Physiologic effects of positive end-expiratory pressure and mask pressure support during exacerbations of chronic obstructive pulmonary disease. Am J Respir Crit Care Med. 1994;149:1069-76.

60. Diaz O, Iglesia R, Ferrer M, et al. Effects of noninvasive ventilation on pulmonary gas exchange and hemodynamics during acute hypercapnic exacerbations of chronic obstructive pulmonary disease. Am J Respir Crit Care Med. 1997;156:1840-1845.

61. Vitacca M, Ambrosino N, Clini E, et al. Physiological response to pressure support ventilation delivered before and after extubation in patients not capable of totally spontaneous autonomous breathing. Am J Respir Crit Care Med. 2001;164:638-41.

62. International Consensus Conferences in Intensive Care Medicine: Noninvasive positive pressure ventilation in acute respiratory failure. Am J Respir Crit Care Med. 2001;163:283-91.

63. Nava S, Ambrosino N, Clini E, et al. Noninvasive mechanical ventilation in the weaning of patients with respiration failure due to chronic obstructive pulmonary disease. A randomized, controlled trial. Ann Intern Med. 1998;128:721-28.

64. Girault C, Daudenthun I, Chevron V, Tamion F, Leroy $\mathrm{J}$, Bonmarchand $\mathrm{G}$. Noninvasive ventilation as a systematic extubation and weaning technique in acute-on-chronic respiratory failure. A prospective, randomized controlled study. Am J Respir Crit Care Med. 1999;160:86-92.

65. Ferrer M, Esquinas A, Arancibia F, et al. Noninvasive ventilation during persistent weaning failure. A randomized controlled trial. Am J Respir Crit Care Med. 2003;168:70-76.

66. Bach JR, Goncalves MR, Hamdani I, Winck JC. Extubation of patients with neuromuscular weakness: a new management paradigm. Chest. 2010;137:103339.

67. Burns KE, Adhikari NK, Keenan SP, Meade M. Use of non-invasive ventilation to wean critically ill adults off invasive ventilation: meta-analysis and systematic review. BMJ. 2009;338:b1574.

68. Ferreyra G, Fanelli V, Del SL, Ranieri V. Are guidelines for non-invasive ventilation during weaning still valid? Minerva Anestesiol. 2011;77:921-26.

69. Epstein SK, Ciubotaru RL, Wong J. Effect of failed extubation on the outcome of mechanical ventilation. Chest. 1997;112:186-92.
70. Esteban A, Alía I, Tobin MJ, et al. Effect of spontaneous breathing trial duration on outcome of attempts to discontinue mechanical ventilation. Am J Respir Crit Care Med. 1999;159:512-18.

71. Epstein SK. Decision to extubate. Intensive Care Med. 2002;28:535-46.

72. Esteban A, Frutos-Vivar F, Ferguson ND, et al. Noninvasive positive-pressure ventilation for respiratory failure after extubation. N Engl J Med. 2004; 350:2452-60.

73. Torres A, Gatell JM, Aznar E, et al. Re-intubation increases the risk of nosocomial pneumonia in patients needing mechanical ventilation. Am J Respir Crit Care Med. 1995;152:137-41.

74. Keenan SP, Powers C, McCormack DG, Block G. Noninvasive positive-pressure ventilation for postextubation respiratory distress: a randomized controlled trial. JAMA. 2002;287:3238-44.

75. Epstein SK, Ciubotaru RL. Independent effects of etiology of failure and time of reintubation on outcome for patients failing extubation. Am J Respir Crit Care Med. 1998;158:489-93.

76. Nava S, Gregoretti C, Fanfulla F, et al. Noninvasive ventilation to prevent respiratory failure after extubation in high-risk patients. Crit Care Med. 2005; 33:2465-70.

77. Ferrer M, Valencia M, Nicolas JM, Bernadich O, Badia JR, Torres A. Early noninvasive ventilation averts extubation failure in patients at risk: a randomized trial. Am J Respir Crit Care Med. 2006; 173:164-70.

78. Ferrer M, Sellares J, Valencia M, et al. Non-invasive ventilation after extubation in hypercapnic patients with chronic respiratory disorders: randomised controlled trial. Lancet. 2009;374:1082-88.

79. El Solh AA, Aquilina A, Pineda L, Dhanvantri V, Grant $B$, Bouquin P. Noninvasive ventilation for prevention of post-extubation respiratory failure in obese patients. Eur Respir J. 2006;28:588-95.

80. Girault C, Bubenheim M, Abroug F, et al. Non-invasive Ventilation and Weaning in Chronic Hypercapnic Respiratory Failure Patients: A Randomized Multicenter Trial. Am J Respir Crit Care Med. 2011; 184:672-79.

81. Thille AW, Harrois A, Schortgen F, Brun-Buisson C, Brochard L. Outcomes of extubation failure in medical intensive care unit patients. Crit Care Med. 2011;39:2612-18. 